\title{
EL PERFECTO SIMPLE Y EL PERFECTO COMPUESTO EN EL ESPAÑOL ACTUAL: ESTADO DE LA CUESTIÓN
}

Silvia Hurtado González

Universidad de Valladolid

\section{RESUMEN}

El propósito de este trabajo es reunir algunas ideas y cuestiones relacionadas con el empleo del perfecto simple y del perfecto compuesto en el español actual. Tras unas consideraciones previas, exponemos las características básicas de ambas formas verbales reflexionando sobre algunos puntos que suscitan opiniones encontradas. Ello es así porque la relación entre ambas formas verbales es bastante complicada, puesto que plantea la imbricación de tiempo y aspecto. En el último apartado hacemos referencia a unos empleos especiales del perfecto simple y del perfecto compuesto que, aunque pueden aparecer en la lengua hablada corriente, surgen con frecuencia en los medios de comunicación social. Se trata de casos en los que no hay correspondencia precisa entre el perfecto y el complemento temporal, pero con los datos disponibles actualmente no es posible predecir si estos usos acabarán consolidándose o bien quedarán limitados a determinadas situaciones comunicativas. 


\section{INTRODUCCIÓN}

El presente trabajo ' tiene como objetivo reunir algunas de las ideas y cuestiones suscitadas en torno a un aspecto muy concreto dentro de la sintaxis verbal de amplísima bibliografía: el perfecto simple y el perfecto compuesto en el español actual. Para ello hemos tenido en cuenta gramáticas, obras que, sin tener carácter de manual, proporcionan informaciones interesantes sobre el tema, y monografías y artículos específicos que se recogen en la exhaustiva bibliografía final. Tratamos de ofrecer un primer acercamiento a este problema a la vez que un apoyo teórico para futuras reflexiones y nuevos caminos de investigación en este campo. Por lo tanto, nos proponemos analizar y reflexionar sobre esta zona del paradigma verbal desde un punto de vista teórico y general, dejando para otra ocasión la discusión minuciosa de algunos puntos.

Es un hecho característico de la conjugación española el uso actual y vivo de las dos formas del perfecto de indicativo canté y he cantado, si bien algunos investigadores extranjeros han señalado que tal distinción es una invención de las gramáticas y que el español usa una u otra forma indistintamente o dependiendo de preferencias personales (Meyer-Lübke, 1974: 134; Bull, 1968: 65; Hanssen, 1945: 226; Paiva Boléo², 1929: 335). Pero para la mayoría de los investigadores existe dicha diferenciación aceptada y mantenida por los hablantes tanto en la lengua hablada como en la escrita, aunque reconoce que no es fácil precisar los motivos de tal distinción. Así es, la relación existente entre ambas formas verbales es, de por sí, bastante complicada, puesto que plantea el problema de la imbricación del aspecto y del tiempo. Trataremos de que la exposición, pese a la complejidad del tema, sea lo más clara posible.

Pero antes hay que recordar que si bien el español dispone, por lo general, de las dos formas, en algunas regiones se han observado preferencias por una de las dos en perjuicio de la otra. En efecto, se ha señalado que en Galicia, Asturias y León la forma compuesta es menos usada y tiende a desaparecer (Gili Gaya: 1970, 160; Real Academia Española, 1973: 466; Alarcos Llorach, 1994: 167), mientras que en Navarra, Aragón y parte de Casti-

Este artículo es una reelaboración de un capítulo de nuestra tesis doctoral: Evolución y usos del perfecto simple y del perfecto compuesto hasta su estabilización, Universidad de Valladolid, 1995 (en microfilm).

${ }_{2}^{2}$ Posteriormente, este filólogo portugués llega a la conclusión de que en muchos casos existe una diferencia de empleo entre el perfecto simple y el compuesto; no obstante, advierte que esa distinción es lingưístico-psicológica más que gramatical. (Cfr. PAIVA Boléo, 1936: 51). 
lla la Vieja están vigentes los dos perfectos (Cerny, 1972: 3). En cuanto a Madrid, encontramos opiniones dispares. Para algunos autores, la forma simple se encuentra en decadencia (Cerny, 1972: 3; Alonso y Henríquez Ureña, 1975: 154-155; Alarcos Llorach, 1994: 167), sobre todo en el habla vulgar madrileña (Gili Gaya, 1970, 160), pero Lamíquiz (1969: 261-262) cree, por su parte, que en Madrid he cantado tiende a desaparecer en beneficio de canté.

Con respecto a estas dos formas en el español de Canarias, también aparecen posturas divergentes. Alvar (1959: 78) señala que la norma de Tenerife, aunque manifiesta cierta preferencia por el perfecto simple en contextos donde la lengua normativa peninsular emplearía el compuesto, no difiere en lo fundamental de la castellana. Almeida (1987-88: 75) incluso hace extensiva esta conclusión al resto del Archipiélago. En este sentido señala Martín Rodríguez (1992: 146) que tales sustituciones no son sistemáticas puesto que, según él, los hablantes siguen utilizando la forma compuesta con los mismos valores que presenta en la norma castellana. Sin embargo, para Diego Catalán (1964: 246), la norma canaria se estructura sobre valores diferentes, siendo la forma simple la única que presenta vitalidad. Asimismo, la preferencia de los canarios por esta forma verbal es señalada por Herrera Santana y Medina Lopez (1991: 227-239), aunque no creen que el español canario difiera de la norma castellana actual.

Tampoco la situación que muestra el español de América parece estar definitivamente resuelta. Hasta hace poco la opinión general era que el perfecto compuesto se utiliza muy rara vez en el español hablado en América, aunque entre los escritores conviven la forma simple y la compuesta (Kany, 1976: 200). Tal estado de cosas se consideraba como confusión de los valores correspondientes a cada una de estas formas verbales. Pero esta aseveración, un tanto apresurada, ha sido revisada por Lope Blanch (1961: 337 385), quien señala que en el español de México la diferenciación entre canté y he cantado obedece a criterios distintos del español peninsular, opinión compartida en líneas generales por otros autores (cfr. Moreno de Alba, 1985). Por otro lado, se ha puesto de manifiesto que hay regiones, como por ejemplo la zona andina ecuatoriana, donde el perfecto compuesto no sólo es una forma con vigencia, sino que incluso ha llegado a adquirir otras funciones desconocidas en el uso peninsular (véase Bustamante, 1991). En cualquier caso, hay que tener en cuenta que las formas verbales que nos ocupan no muestran idénticas funciones en las variedades del castellano peninsular y americano aunque, como advierte Gutiérrez Araus (1995: 21), la oposición no es diferente en todos los usos de España y América, sino que algunos de ellos coinciden. 
2. El PERFECTO SIMPLE Y EL PERFECTO COMPUESTO: CARACTERÍSTICAS BÁSICAS

Pero dejando a un lado todas estas consideraciones y centrándonos exclusivamente en la norma peninsular, las formas canté y he cantado coinciden en significar hechos anteriores al momento del hablante, sólo que las respectivas acciones pasadas que significan, aparte de que se pueden situar en puntos diferentes del eje temporal, no guardan la misma relación con el presente.

En cuanto al perfecto simple, la mayoría de los autores, implícita o explícitamente, reconoce que expresa acciones 'perfectas', esto es, acabadas en el pasado (valor aspectual perfectivo). Sin embargo, para resolver el problema del carácter perfectivo de este pretérito con verbos imperfectivos o permanentes en los que se da una prolongación indefinida del proceso se hace hincapié en el aspecto incoativo que asumen las expresiones construidas con este tipo de verbos (Bello, 1981: 401) ${ }^{3}$.

También se insiste en otra característica: el valor puntual (Gili Gaya, 1973: 157; Criado de Val, 1948: 100), entendido normalmente como acción momentánea o acción breve y de duración precisa que no atiende ni al desarrollo de la acción ni a sus posibles consecuencias.

Lo cierto es que en las gramáticas se suele llamar la atención sobre la influencia que puede ejercer el semantismo verbal, es decir, el valor semántico de la raíz verbal en la significación de esta forma verbal (Cfr. Hernández Alonso, 1996: 429); esto es, se concede importancia al hecho de que sea imperfectivo o perfectivo su modo de acción.

Por otra parte, desde un punto de vista temporal, Criado de Val (1948: 96), por ejemplo, sostiene que la forma simple corresponde preferentemente a la expresión de un pasado remoto más o menos lejano con respecto al 'ahora' enunciativo, y en todo caso, a un hecho más apartado del presente del que expresa la forma compuesta.

Dado los imprecisos límites existentes entre los conceptos de lejanía / proximidad, ha surgido la siguiente interpretación: 'cerca' = dentro del día y 'lejos' = fuera del día, que no es exactamente lo mismo que decir que cuando en el enunciado aparecen unidades temporales que se refieren a un período de tiempo ya concluido, se usa el perfecto simple, formulación esta última que aparece expresada más o menos así en muchas gramáticas y estudios.

Lo que parece claro es que esta forma verbal posee un significado desligado de cualquier relación con el momento en que hablamos, es decir, por sí

${ }^{3}$ BOLINGER (1963: 134) y BAUHR (1987: 343), por el contrario, sostienen que esta pretendida incoatividad del pretérito simple se basa en una mala interpretación de los datos. 
misma no indica conexión alguna con el presente. Precisamente por esta significación es considerada como la forma verbal más adecuada para la narración, ya que marca secuencias de acciones ocurridas en el pasado que hacen avanzar la historia. Por el contrario, en los relatos no suele aparecer el perfecto compuesto. Esto significa que la frecuencia de uso de cada de estas formas está muy condicionada por el registro y el tipo de texto ${ }^{4}$. Sobre ello volveremos más adelante.

Por otro lado, las diferentes gramáticas señalan características muy semejantes para el perfecto compuesto. Todas ellas coinciden en atribuir a esta forma verbal el valor de acción pasada y perfecta pero que guarda una relación con el presente. Ahora bien, el problema reside en cómo se interprete tal conexión con respecto al acto de habla. Como señala Berschin (1975: 550), en la bibliografía suelen aparecer unidos el criterio de conexión de un acontecimiento pasado con el acto de habla y el criterio de orientación hacia el momento del habla entendido en el sentido de que un acontecimiento se realiza (o no, en la negación) hasta el momento del habla, es decir, 'hasta ahora'. Así, aparece como expresión de una acción que, aun perteneciendo al pasado, continúa en el presente y se presenta como no terminada, como una acción o estado cuyos efectos o resultados perduran en el momento de la enunciación. Por sus resultados aún relevantes, he cantado se asocia al presente.

Considerando la inclusión de la acción verbal con respecto al acto de habla, si hay unidad temporal expresa en la frase y esta unidad abarca el momento en que hablamos, es decir, si se trata de un período de tiempo que no ha terminado todavía, la forma utilizada es el perfecto compuesto. Dicho intervalo de tiempo no posee limitaciones en cuanto a su longitud, esto es, puede ser todo lo dilatado que se quiera con tal que se abarque el momento presente, lo cual permite a Alarcos Llorach hablar del 'presente ampliado', un período desde un punto del pasado hasta el 'ahora' en que se habla o escribe.

En cambio, otros autores consideran que el mejor índice de la conexión con el acto de habla es la proximidad temporal. Según esto, el perfecto compuesto se conecta con el presente por su significado de inmediatez. Y así, también puede aparecer con adverbios o expresiones temporales muy cercanas al presente: últimamente, recientemente, hace unos momentos... (Sastre, 1995: 56).

Pero como apunta Moreno de Alba (1985: 44), la relación que un pasado guarda con el presente no necesariamente es proporcional a la distancia cronológica que lo separa del momento de la enunciación: una acción pasa-

4 Para la frecuencia de uso de ambas formas por etapas y tipos de texto a lo largo de la Edad Media, véase nuestro artículo «Estudio cuantitativo del perfecto simple y compuesto en el período medieval", en RICUS (Filología), Soria, XIII, 1, 1997, pp. 149-162. 
da puede tener relación con el presente aunque cronológicamente esté muy alejada. Alarcos (1982: 33) señala con toda claridad que la mayor o menor distancia cronológica entre la acción expresada y el momento de la enunciación no es relevante, sino el que esa acción tenga relación con el presente en el sentido de que se trate de hechos que ocurren dentro de un período de tiempo que incluya el acto de habla, tal como ya hemos señalado. De hecho, una misma acción alejada del presente gramatical puede expresarse con las dos formas según el adverbio que la acompañe (Hace tres meses estuve en Londres, pero Este año he estado en Londres). De ahí se deduce que el complemento temporal, cuando aparece, parece determinar la elección de una u otra forma. Insistamos en esta cuestión: cuando tenemos una referencia temporal explícita, canté se utiliza con expresiones como ayer, la semana pasada, el año pasado..., mientras que he cantado expresa acciones que sí llegan temporalmente al momento del hablante (hoy, esta semana, este mes, este año..). Así, con determinados adverbios o complementos análogos parece clara la vinculación o desvinculación con el presente, aunque en ocasiones no se necesita una referencia temporal explícita porque es suficiente con la situación y el contexto comunicativos, como sucede en la conversación y el coloquio.

De cualquier modo, se insiste de una u otra manera en la relación que he cantado guarda con el momento presente. Como acabamos de ver, con determinados adverbios o complementos parece clara la relación con el presente, pero este enlace puede resultar una noción relativa, sobre todo en ausencia de tales complementos.

Harris (1982: 45) destaca el hecho de que este concepto de relevancia presente, considerado como prototípico del perfecto español, es inherentemente subjetivo y potencialmente inestable, lo que hace que pueda variar considerablemente.

En este sentido se señala que el hablante puede expresar con esta forma verbal su relación emocional y subjetiva hacia el contenido de la oración. En casos como Mi padre ha muerto hace tres años la relación con el presente no es real, sino subjetiva y particular, y por lo tanto, condicionada por factores de tipo expresivo. Así es, ciertos factores expresivos pueden influir en la elección de la forma compuesta. Incluso, ante la dificultad de establecer reglas precisas, a veces se piensa que ese factor de 'conexión con el acto de habla' expresa simplemente el hecho de que el empleo del perfecto compuesto tiene carácter subjetivo o afectivo para el que habla. La valoración por parte del hablante de la relación entre acto de habla y acontecimiento es un hecho pragmático; en consecuencia, el criterio de 'conexión con el acto de habla' puede ser entendido como un factor semántico-pragmático (Berschin, 1975: 553). 
Sin embargo, estamos de acuerdo con Alarcos Llorach (1982: 21) al rechazar la opinión de que sólo la forma compuesta está determinada subjetivamente. En nuestra opinión, es la elección de una u otra forma lo subjetivo, no el resultado de tal elección. Es decir, en ocasiones sólo el juicio del hablante, personal y particular, determina la presencia o ausencia de la relación con el presente, y de ahí la elección de una u otra forma. La selección depende de lo que Alarcos describe simplemente como 'sentimiento personal'.

Hasta aquí, hemos visto que no se suelen considerar como relevantes en la diferencia de empleo entre los dos perfectos criterios aspectuales, como sostiene Alarcos Llorach en su estudio, cuyos juicios han tenido un gran peso en las investigaciones posteriores. La distinción parece depender únicamente de factores temporales, aunque a veces estos factores se determinen subjetivamente. En efecto, para la mayoría es la visión temporal que el hablante tiene lo que realmente importa. No obstante, Alarcos considera el 'tiempo' no sólo como una circunstancia objetiva, sino como un contenido de conciencia, y por tanto, subjetivo. Él explica claramente cuándo la distinción es objetiva y cuándo es subjetiva. En los casos en que la temporalidad no va marcada externamente, como ya hemos insinuado, el concepto de 'presente ampliado' es puramente subjetivo, en cuyo caso puede utilizarse una u otra forma, según se entienda el pasado como opuesto al presente o como prolongación del mismo. Pero las unidades temporales están presentes en el pensamiento, aunque no expresadas, ya que hay siempre en el pensamiento del que habla una temporalidad y ésta hará, según su valor, escoger la forma verbal que más convenga a su significado. En caso de que sí haya algún tipo de referencia temporal explícita, se considera que tiene que haber una correlación entre los adverbios de tiempo o complementos similares y los usos de los dos perfectos, ya que se exigen mutuamente, aunque no hay que pasar por alto que existe una zona de temporalidad pasada en la que los dos pretéritos pueden usarse indistintamente: con adverbios y complementos temporales que indican duración o repeticion, si bien con la forma compuesta se indica que la acción se ha producido repetidamente o dura hasta el presente (una acción producida en el 'presente ampliado'), mientras que con la simple se indica que la acción tuvo un término en el pasado (Alarcos, 1982: 27), es decir, por sí mismas marcan la diferencia de sentido temporal. Pero aunque con este tipo de modificaciones temporales durativas e iterativas pueda usarse tanto el perfecto simple como el compuesto, con siempre y nunca el perfecto compuesto es más frecuente (Paiva Boléo, 1936: 46). Por su parte, Otálora Otálora (1970: 27) cree que en estos casos la forma compuesta es la predominante, la que está más definitivamente sancionada por el uso idiomático. 
Por otra parte, retomando una cuestión pendiente, el perfecto compuesto es considerado como una forma apropiada para el coloquio y el comentario. Como ya hemos señalado, un plano en el que la diferencia entre el perfecto simple y el compuesto se manifiesta con claridad es en el diferente uso que de estas formas se hace en la narración y en el coloquio.

Como en la lengua corriente es frecuente el comentario y en la lengua literaria, la narración, Paiva Boléo (1936: 53) sostiene que en la lengua hablada común la forma verbal compuesta es más frecuente que la simple, lo cual no significa que un perfecto esté suplantando al otro. Para Criado de Val (1948: 124) la forma compuesta es la adecuada para el diálogo dramático, lo que justificaría su mayor frecuencia en las obras teatrales. Por ello tiene mucha importancia el tipo de texto en el que se basen los recuentos. Sin embargo, Criado de Val (1948: 103) señala en otro momento la mayor impulsividad y viveza del pretérito en comparación con el perfecto, e indica que son causas eufónicas las que en multitud de ocasiones determinan su empleo o sustitución por la forma compuesta. También para Paiva Boléo (1936: 41) son determinantes las causas de orden afectivo y estético o eufónico, aunque este filologo portugués $(1936,42)$ considera que por lo general es la forma compuesta la más usada para expresar impulsos o afectos. Alarcos Llorach (1982: 34), por su parte, acepta la idea de que, a veces, el elemento afectivo puede determinar el empleo de la forma compuesta, pero no está de acuerdo con Paiva Boléo al exponer que son razones estéticas o eufónicas las que condicionan el empleo de una de las dos formas. En realidad, no resulta convincente Paiva Boléo (1936: 42) cuando señala que se emplea el perfecto compuesto para evitar la forma irregular (por ejemplo, he andado en lugar de anduve), aparte de que no es mucho lo que se adelanta con afirmaciones de este tipo.

\section{OTRAS CONSIDERACIONES}

Es cierto que normalmente se espera que exista una correspondencia precisa entre la perspectiva de temporalidad que el pretérito expresa y la constatada por el complemento temporal, pero aunque en general, como explica Otálora Otálora (1970: 28), debe darse dicha correspondencia, esto no quiere decir que el complemento determine el perfecto que se ha de usar, puesto que ambos están relacionados fenomenológicamente. Si no tenemos esa correspondencia, la expresión resulta poco idiomática.

Dejando a un lado los casos en los que el intercambio parece posible, en ocasiones se emplea el perfecto simple o el compuesto aun estando acompañados del mismo complemento temporal, lo que pone de manifiesto la relatividad 
de las reglas antes enunciadas: basta en principio un caso en que hoy, por ejemplo, se combine con el perfecto simple o ayer con el compuesto. Y como veremos enseguida, no es difícil encontrar muestras de este tipo.

En efecto, aparecen casos en los que no se da la correspondencia precisa entre el complemento temporal y el pretérito usado, por lo que parece haber una dislocación del significado básico o bien una suplantación de un perfecto por otro. Así, teniendo en cuenta el panorama de distinciones antes expuesto, pueden resultar hasta cierto punto extraños enunciados como los siguientes: Ayer se ha clausurado el simposio, El mes pasado ha bajado el índice de precios al consumo, Hoy se clausuró el simposio, Esta semana se celebró el festival de cine. Desde ayer ardieron quinientas hectareas del parque nacional, ejemplos entresacados de los medios de comunicación social por Alcoba Rueda (1990: 90), aunque no son exclusivos de este tipo de situación comunicativa. Por una parte, se trata de enunciados en que se usa el perfecto simple para expresar el antepresente o pasado inmediato (Hoy los Reyes visitaron el Museo del Prado), y por otra, la forma compuesta es usada con significados que pertenecen a un pasado muy remoto sin que este significado se continúe hasta el presente o implique duración alguna una vez realizado, remitiendo el complemento la acción directa y específicamente a un momento del pasado (Ayer he visto a Juan). Parece que son relativamente más frecuentes los casos en que se usa la forma simple para expresar el antepresente inmediato, ya que, según Otálora Otálora (1970:26, 27), el empleo de la forma compuesta por la simple es escaso y limitado a ciertos verbos.

No existe unanimidad sobre si tales usos son gramaticales o no, aunque no se puede negar que son usos aceptables semántica y comunicativamente. Pero por ejemplo, a Carnicer (1972: 174) le parece que mientras podemos decir Hoy vi al señor García, resulta anómalo Ayer he visto al señor García. Para algunos estudiosos (Gutiérrez Araus, 1994: 115), no es normativo este último enunciado, puesto que si se fija la acción en un punto concreto del pasado, sólo se puede emplear el perfecto simple, mientras que otros incluyen dicho empleo entre los usos normales del perfecto compuesto (Graciela Reyes, 1994: 115). En opinión de Berschin (1975: 548), «en español peninsular ayer es incompatible con el perfecto compuesto, pero hoy se combina con ambos perfectos.» Paiva Boléo (1936: 39), por el contrario, no encuentra ningún ejemplo de hoy con perfecto simple, y deduce que ningún español diría hoy murió. Teniendo en cuenta los años que separan ambos estudios, cabe pensar que los empleos a los que estamos haciendo referencia en este apartado, son relativamente recientes.

A este respecto, se ha destacado el creciente desuso de ha cantado en favor de cantó en la prensa, la radio y la televisión. De los Mozos (1984: 71) po- 
ne como ejemplo de lo que a veces se comunica el siguiente enunciado: oyeron la tercera sinfonía de Beethoven. Ya algunos años antes Skubic (1968: 1.892) había notado que Radio España en su diario de noche comentaba los hechos ocurridos el mismo día usando tanto el pretérito compuesto como el simple. Le suscita un interés particular los comentarios de los enviados que a veces terminan con la forma simple: Desde Berlín informó... (junio, 1965).

También señala Lapesa (1977: 228) que en los titulares de prensa y en las emisiones radiofónicas se prefiere el perfecto simple para hechos recientes o inmediatos. Este autor no excluye ocasionales resabios del Noroeste peninsular, si bien señala que en este resurgimiento "parecen haberse juntado influjos del inglés estadounidense y del español americano, uno y otro apegados al perfecto simple.»

Según Romero Gualda (1993: 36), el perfecto simple parece usarse indiscriminadamente, sobre todo en los medios audiovisuales, pero a esta autora le resulta curioso que unos medios que se caracterizan por la comunicación inmediata y la aproximación al receptor elijan la forma verbal que expresa el alejamiento y el acabamiento de la acción. Sin embargo, Alcoba Rueda (1990: 90), aunque advierte este peculiar uso, no destaca su predominio en el lenguaje periodístico. Así, como ya hemos señalado, es posible encontrar ejemplos como Hoy se clausuró el simposio, pero también pueden aparecer casos como Ayer se ha clausurado el simposio.

Sobre cuál de los dos perfectos es más usado en la prensa escrita, Paiva Boléo (1936: 49) señala que en los titulares de los periódicos aparece ya el pretérito ya el perfecto, aunque en su opinión es más usado el perfecto. Según él, parece que el significado del verbo tiene alguna influencia. Pero a Alarcos Llorach (1982: 47) no le parece cierta tal afirmación, ya que el empleo de una u otra forma depende del carácter del escrito. Observa este autor que en los periódicos es más usado el perfecto simple debido a que se suelen narrar hechos y no presentar diálogos. Así, según el tema, predomina el perfecto simple o el perfecto compuesto.

En realidad, el uso y frecuencia de estas formas verbales en los medios de comunicación no ha sido debidamente examinada. Las afirmaciones que acabamos de exponer están basadas en una documentación bastante limitada, por lo que dichas conclusiones han de ser tomadas con cautela a la espera de ser confirmadas en estudios más minuciosos. Y en cuanto al estudio de la prensa escrita, creemos que hay que estudiar por separado el titular y el cuerpo de la noticia, ya que el titular presenta unos rasgos diferenciadores muy acusados por tratarse de unidades privilegiadas al estar destacadas gráficamente.

Por último, podemos preguntarnos qué es lo que se pretende con estos empleos. En cuanto al uso de la forma simple por la compuesta, según Otá- 
lora Otálora (1970: 27), responde a una necesidad de expresividad enfática. Explica que con este uso se tiende a destacar objetivamente el hecho en cuestión, para lo cual se usa un signo verbal que automáticamente destaca el pasado.

En cuanto a los casos en que el perfecto se refiere a un momento específico del pasado porque el complemento remite la acción a un determinado momento del pasado, Otálora Otálora (1970: 28) cree que quizá se puedan explicar estos usos por la existencia de cierto estado emocional, debido al cual el hablante quiere atraer el pasado hacia el presente en la medida de lo posible con el fin de mostrar que siente la acción como actual.

Pero para este estudioso (1970: 24), el empleo del perfecto compuesto para indicar una acción limitada al pasado no es de empleo peninsular, sino madrileño especialmente, y limita tal uso al 'habla popular'. Sin embargo, según De Mello (1994: 617), esta construcción con tener una distribución geográfica bastante limitada, o sea, con ser un fenómeno regional, no se limita a Madrid. También se encuentra en el habla sevillana (De Mello, 1994: 619). Asimismo, sostiene que esta construcción no es de ninguna manera vulgar o inculta (De Mello, 1994, 622).

Algunos autores señalan la proximidad temporal como requisito para este empleo (Berschin, 1975: 543), pero el estudio de De Mello no corrobora esta hipótesis.

De Mello (1994: 624) realiza un análisis de los casos del empleo del pretérito simple y el pretérito compuesto con expresiones temporales de «hace», que indican la distancia respecto al habla y no estrictamente un período de tiempo, y llega a la conclusión de que ambos pretéritos se utilizan tanto con tiempo próximo como con tiempo lejano.

Observa también que si bien en un buen número de estos casos el evento a que se refiere el hablante es reciente (Eso lo he visto hace poco), sin embargo, son muchos los ejemplos en que el momento presente se relaciona con el pasado no por proximidad temporal sino en forma más subjetiva, en definitiva, por razones de afectividad muchas veces difíciles de reconocer (De Mello, 1994: 628). Prueba de ello es que aparecen en un alto porcentaje con verbos en primera persona singular o plural (De Mello, 1994: 630). Otra evidencia de la importancia de la afectividad se encuentra en las citas de su corpus en las que, aunque haya pasado mucho tiempo entre el evento descrito y el momento de habla, la informante utiliza el pretérito compuesto.

Así, De Mello (1994: 627) sugiere que la explicación del empleo del perfecto compuesto para la expresión de una acción limitada al pasado no reside en nociones de proximidad temporal, sino en otros motivos como la emotivi- 
dad, o sea, un tipo de afectividad, ya que indica algún tipo de acercamiento del pasado al presente del hablante (1994: 628). Otálora Otálora (1970: 28) también lo interpreta así, según hemos visto.

El estudio de De Mello está en la misma línea de varios lingüistas que sostienen que el impulso principal para el empleo del pretérito compuesto reside en nociones de afectividad, la cual, según De Mello, posiblemente incluye, aunque no se limita, a consideraciones de proximidad temporal.

En todo caso, creemos que tanto en el empleo del perfecto simple para expresar el pasado inmediato como en el empleo de la forma compuesta con acción limitada al pasado se quiere de algún modo destacar o dar relieve al acto que el verbo representa, aunque en última instancia la carga expresiva y afectiva depende de la intención del hablante o escritor. Y con respecto a su aparición en los medios de comunicación, no hay que olvidar que el lenguaje periodístico tiende a realizar unos usos especiales como pretendidas señas diferenciadoras de su modo de comunicación. No obstante, a veces lo único que se consigue es un choque expresivo entre la forma del verbo y la forma del adverbio que hace que la expresión resulte un tanto rara, impactando al lector u oyente, pero por lo contradictorio.

Puede que alguno de estos usos se consolide con el tiempo. Es posible porque el lenguaje cambia y se renueva constantemente, pero de momento no podemos predecir la suplantación de un perfecto por otro, tal como ha ocurrido en otras lenguas.

\section{BIBLIOGRAFIA}

Alarcos Llorach, Emilio (1947): «Perfecto simple y compuesto", Revista de Filología española, XXXI, pp. 108-139. También en Estudios de Gramática Funcional del Español, (1982), 3. ${ }^{\circ}$ ed. Madrid, Gredos, pp. 13-49.

- (1994): Gramática de la lengua española, Madrid, Espasa Calpe.

alcina Franch, Juan y José Manuel Blecua (1983): Gramática española, Barcelona, Ariel.

Alcoba Rueda, Santiago (1990): "Muestras de inestabilidad sintáctica en el discurso de la aldea McLuhan», en Asociación de la Prensa de Zaragoza (ed.): El lenguaje en los medios de comunicación, Zaragoza, pp. 73-102.

Almeida, Manuel (1987-88): «Perfecto simple y perfecto compuesto en el español de Canarias», Revista de Filología, Universidad de La Laguna, 6-7, pp. 69-77

- (1989): El habla rural grancanaria, La Laguna, Universidad.

Almeida, Manuel y Carmen Díaz Alayón (1989): El español de Canarias, Santa Cruz de Tenerife, A. Romero. 
Alonso, Amado y Pedro Henrfquez Ureña (1975): Gramática castellana, 25a ed., Buenos Aires, Losada.

Alonso, Martín (1974): Gramática del español contemporáneo, Madrid, Ediciones Guadarrama.

Alvar, Manuel (1953): El dialecto aragonés, Madrid, Gredos.

- (1959): El español hablado en Tenerife, Anejo LXIX de la Revista de Filología Española, Madrid, CSIC.

- (1976): El dialecto riojano, Madrid, Gredos.

Barrera VIDA, Albert: Parfait simple et parfait composé en castillan moderne, Munich, Max Huber, 1972.

Bauhr, Gerhard (1987): «'Dijo Dios, sea la luz, y la luz fue’, ¿cambio aspectual?», Revista Española de Lingüística, 17/2, pp. 341-346.

BeINHAUER, Werner (1968): El español coloquial, Madrid, Gredos.

BELlo, Andrés (1981): Gramática de la lengua castellana, destinada al uso de los americanos (ed. crítica de R. Trujillo), Cabildo Insular de Tenerife, Instituto Universitario de Lingüística Andrés Bello.

Bentivoglio, Paola y Mercedes Sedano (1992): «El español hablado en Venezuela», Historia y presente del español en América, Valladolid, Junta de Castilla y León, pp. 775-802.

Berschin, Helmut (1975): «A propósito de la teoría de los tiempos verbales. Perfecto simple y perfecto compuesto en el español peninsular y colombiano», Thesaurus, BICC, XXX, pp. 539-556.

BOLINGER, DWIGHT L. (1963): «Reference and inference: inceptiveness in the Spanish preterit", Hispania, XLVI, pp. 121-135.

Bull, William E. (1947): «Modern Spanish Verb-form Frequencies», Hispania, XXX, pp. 451-466.

- (1968): Time, Tense and Verb. A Study an Theoretical and Applied Linguistics with Particular Attention to Spanish, Berkeley, University of California.

BustamANTE, ISABEL (1991): «El presente perfecto o pretérito perfecto compuesto en el español quiteño", Lexis, XV, 2, pp. 195-231.

CARNICER, RAMÓN (1972): «Dos pretéritos», en Nuevas reflexiones sobre el lenguaje, Madrid, Prensa Española, pp. 173-177.

Catalán, Diego (1964): «El español en Canarias», Presente y Futuro de la Lengua Española, I, Madrid, pp. 239-280.

- (1966): «El español en Tenerife. Problemas metodologicos», Zeitschrift für Romanische Philologie, 82, pp. 467-506.

CERNY, JIRI (1970): "El pretérito español y la categoría del aspecto», Actas del XII Congreso Internacional de Lingüística y Filología Románicas, Bucarest, I, pp. 787-792.

- (1972): «Tiempos pretéritos compuestos y la estructura del sistema verbal», Español Actual, 22, pp. 1-10. 
CORBELlA, DOLORES (1987): «Algunos datos estadísticos del paradigma verbal español», In Memoriam Inmaculada Corrales, I, La Laguna, Universidad, pp. 145159.

Criado de VAl, MANuel (1948): Sintaxis del verbo español moderno. I. Metodología. II. Tiempos pasados del indicativo, Anejo XLI de la Revista de Filología Española, Madrid, CSIC.

- (1951): «Sistema verbal del español. Notas para una sintaxis hispanorrománica», Vox Románica, 12, 5, pp. 95-111.

- (1969): El verbo español, Madrid, SAETA.

- (1972): Gramática española, Madrid, SAETA.

De Kock, Josse (1984): «El pretérito perfecto compuesto y las indicaciones de tiempo extraverbales», Revista de Filología Románica, 2, pp. 103-112.

- (1986): «Del pretérito perfecto compuesto o de la importancia del contexto y de la cuantificación», Revista de Filología Española, LXVI, pp. 185-236

- (1990): Gramática española: Enseñanza e Investigación. II. Gramática. 3. Del pretérito perfecto compuesto y de la cuantificación. La noción de auxiliaridad, Salamanca, Universidad.

- (1991): «Pretéritos perfectos simples y compuestos en España y América», El español de América, I, Salamanca, Junta de Castilla y León, pp. 481-492.

De Mello, George (1994): «Pretérito compuesto para indicar acción con límite en el pasado: "Ayer he visto a Juan'», Boletín de la Real Academia Española, LXXIV, pp. 611-631.

DONNI DE MiRANDE, Nélida (1992): «El español actual hablado en la Argentina», Historia y presente del español de América, Valladolid, Junta de Castilla y León, pp. 383-411.

FernÁNDEZ RAMíRez, SALVADOR (1986): Gramática española 4. El verbo y la oración (volumen ordenado y completado por Ignacio Bosque), Madrid, Arco Libro.

García DE Diego, Vicente (1970): Gramática histórica española, Madrid, Gredos.

GARCIA HERNÁNDEZ, BENJAMf́n (1977): «El sistema del aspecto verbal en latín y en castellano", Studia Philologica Salmanticensia, 1, pp. 65-114.

Gili GAYA, SAMUEL (1973): Curso superior de sintaxis española, $11^{2}$ ed., Barcelona, Vox.

- (1972): «El pretérito de negación implícita», Studia Hispánica in honorem R. Lapesa, 1, Madrid, Gredos, pp. 251-256.

GuttérRez ARAUS, M. ${ }^{a}$ LuZ (1995): Formas temporales del pasado en indicativo, Madrid, Arco Libro.

HANSSEN, FEDERICO (1945): Gramática histórica de la lengua castellana, Buenos Aires, El Ateneo.

Harris, Martín (1982): «The 'Past simple' and the 'Present Perfect' in Romance», Studies in the Romance Verb (ed. N. Vincent y M. Harris), Londres, Croom Helm, pp. 42-7. 
Hernández Alonso, CÉsar (1973): «Sobre el tiempo en el verbo español», Revista Española de Lingüística, 3/1, Madrid, pp. 143-178.

- (1975): Sintaxis española, Valladolid.

- (1977): Lengua español, Madrid, UNED.

- (1996): Gramática funcional del español, $3^{\text {a }}$ ed., Madrid, Gredos.

Herrera Santana, Juana y Javier Medina López (1991): «Perfecto simple/perfecto compuesto: análisis sociolingüístico», Revista de Filología, Universidad de La Laguna, 10, pp. 227-239.

KaNy, Charles (1976): Sintaxis hispanoamericana, Madrid, Gredos.

Keniston, Hayward (1937): The Syntax of Castilian Prose: The Sixteenth Century, Chicago, University of Chicago.

Kubart, Hugo (1992): «El uso del pretérito simple y compuesto en el español hablado en Buenos Aires", Scripta Philologica In Honorem J. M. Lope Blanch, México, UNAM, pp. 553-566.

LAMfQUIZ, VIDAL (1969): «El sistema verbal del español actual. Intento de estructuración", Revista de la Universidad de Madrid, XVIII, pp. 241-265.

- (1972): Morfosintaxis estructural del verbo español, Sevilla, Universidad.

- (1982): El sistema verbal español, Málaga, Ágora.

- (1987): Lengua española, Barcelona, Ariel.

LAPESA, RAFAEL (1977): «Tendencias y problemas actuales de la lengua española», en Comunicación y lenguaje, Madrid, Karpos, pp. 207-229.

LENZ, Rodolfo (1925): La oración y sus partes, Madrid, Centro de Estudios Históricos.

LOPE BLANCH, JUAN M. (1961): «Sobre el uso del pretérito en el español de México», Studia Philologica, Homenaje a Damaso Alonso, II, Madrid, pp. 373-386. También en Estudios sobre el español de México (1983), México, UNAM, pp. 131-143.

- (1968): «La reducción del paradigma verbal en el español de México", Actas del XI Congreso Internacional de Lingüística y Filología Románicas, IV, Anejo LXXXVI de la Revista de Filología Española, Madrid, pp. 1.791-1.808. También en Estudios sobre el español de México (1983), México, UNAM, pp. 145-159.

LORENZO, EMILIO (1971): El español de hoy, lengua en ebullición, Madrid, Gredos. Marcos Marin, Francisco (1975): Aproximación a la gramática española, $3^{\text {a }}$ ed., Madrid, Cincel.

- (1980): Curso de gramática española, Madrid, Cincel.

MARTín Rodríguez, ÁNGEL. (1992): «Usos del indicativo en el español de Canarias», Revista de Filologia, Universidad de La Laguna, 11, pp. 141-150.

MEIER, HARRI (1970): «Sintaxis verbal española, peninsular e hispanoamericana», Actas del III Congreso Internacional de Hispanistas, México, pp. 601-610.

Mendoza Quiroga, José G. (1992): "Aspectos del castellano hablado en Bolivia», Historia y presente del español de América, Valladolid, Junta de Castilla y León, pp. 437-500. 
MEYER-LuBKE, W.: Grammaire des Langues Romanes (trad. A. et G. Doutrepont), 4 vols., Genève-Marseille, Slatkine-Lafitte Reprints, 1974.

MOLHo, MAURICE (1975): Sistemática del verbo español (Aspectos, modos y tiempos), 2 vol., Madrid, Gredos.

Morales, Amparo (1992): «El pretérito compuesto en el español de Puerto Rico: adquisición del lenguaje y norma del adulto», Scripta Philologica. In Honorem J. M. Lope Blanch, México, UNAM, pp. 627-639.

MoRENo DE ALBA, JosE G. (1977): «Frecuencias de formas verbales en el español hablado en México", Estudios sobre el español hablado en las principales ciudades de América, México, UNAM, pp. 115-128.

- (1985): Valores de las formas verbales en el español de México, $2^{\mathfrak{a}}$ ed., México, UNAM.

- (1988): El español de América, México, FCE.

- (1992): «El español hablado en México», Historia y presente del español de América, Valladolid, Junta de Castilla y León, pp. 627-648.

Mozos, SANTIAGo dE Los (1984): «Sobre verbos. III. Cantó y ha cantado», en La norma castellana del español, Valladolid, Ámbito.

OTÁLORA OTÁLORA, GASPAR (1970): «El perfecto simple y compuesto en el actual español peninsular», Español Actual, 16, pp. 24-28.

Paiva BolÉo, Manuel de (1929): «Génesse do conceito de 'tempo passado' e sua expresâo nas línguas románicas», en Biblos, pp. 315-340.

- (1936): $O$ Perféito e o Pretérito em português em confronto com as outras línguas romanicas, Cursos e Conferência da Biblioteca da Universidade, VI, Coimbra.

PARKer, E.F. (1928): «Ignored Values of the Preterit Tense», Hispania, XI, pp. 218220.

Pérez Rioja, J. A. (1968): Gramática de la lengua española, $6^{\sharp}$ ed., Madrid, Tecnos. RAllides, C. (1971): The Tense-Aspect System of the Spanish Verb, The Hague, Mouton.

ReAl ACADEMIA Española (1931): Gramática de la lengua española, Madrid, Espasa Calpe.

- (1973): Esbozo de una nueva gramática de la lengua española, Madrid, Espasa Calpe.

Reyes, Gractela (1994): La pragmática lingüistica. El estudio del uso del lenguaje, $2^{\mathrm{a}}$ ed., Barcelona, Montesinos.

Rivarola, J. L. (1980): «Review of Berschin, H. (1976)», Zeitschrift für Romanische Philologie, 96, pp. 235-238

ROJO, GUILlERMO (1988): «Temporalidad y aspecto en el verbo español», Lingüistica española actual, 10, pp. 195-216.

Romero GuAlda, M." Victoria (1993): El español en los medios de comunicación, Madrid, Arco Libro. 
Sánchez MÁRquez, MANuel J. (1982): Gramática moderna del español. Teoría y norma, 2." ed., Buenos Aires, Ediar.

Sastre Ruano, M. Ángeles (1995): El indicativo, Salamanca, Ediciones Colegio de España.

Seco, Manuel (1980): Gramática esencial del español, $7^{\text {a }}$ reimpr., Madrid, Aguilar.

SECO, RAFAEL (1978): Manual de gramática española (revisado y ampliado por Manuel Seco), 10. ed., Madrid, Aguilar, 1978.

SEIFERT, Eva (1952): «Sobre E. Alarcos Llorach: perfecto simple y compuesto en español», Anales del Instituto de Lingüística, 5, pp. 395-398.

- (1952): «Sintaxis del verbo español moderno», Anales del Instituto de Lingüistica, 5, pp. 398-404.

SerRano, M. ${ }^{a}$ José (1994): «Del pretérito indefinido al pretérito perfecto: un caso de cambio y gramaticalización en el español de Canarias y Madrid», Lingüística española actual, XIV, 1, pp. 37-57.

SkUBic, Mrtua (1964): «Pretérito simple y compuesto en el español hablado», Lingüística, 6, Eslovenia, pp. 87-90.

- (1968): «Pretérito simple y compuesto en los primeros textos castellanos», Actas del XI Congreso Internacional de Lingǘstica y Filología Románicas, IV, pp. 1.891-1.901.

SlawomiRski, J. (1983): «La posición del aspecto en el sistema verbal español», $R e$ vista Española de Lingüística, 13/1, pp. 91-119.

SCHWENTER, S. (1994): «The grammaticalization of an anterior in progress: evidence from a peninsular Spanish dialect», Studies in Language, 18, pp. 71-111.

SPERBER, D. y D. WILSON (1986): Relevance. Communication and Cognition, London, Blackwell.

Torre, Santiago de la (1991): Normativa básica del uso del español, Madrid, Paraninfo.

VARgas Barón, Anf́bal (1953): «Los tiempos del indicativo», Hispania, 36, pp. 412-419.

VEIGA, ALEXANDRE (1987): Valores de las formas verbales en castellano (extracto de Tesis Doctoral), Santiago de Compostela, Universidad.

WEINRICH, HARALD (1968): Estructura y función de los tiempos en el lenguaje, Madrid, Gredos.

Westmoreland, M. (1988): «The distribution and the use of the present perfect and the past perfect forms in American Spanish», Hispania, 71, 2, pp. 378-384.

Wilson, D. y D. SPERBER (1993): «Linguistic form and Relevance», Lingua, 90, pp. 1-25.

WotjaK, G. y A. Veiga (coord.) (1990): La descripción del verbo español, Anexo 32 de Verba, Santiago de Compostela, Universidad. 